\title{
Regionalização do Sistema Único de Saúde - SUS entre municípios conurbados: a problemática dos recursos financeiros
}

\author{
Milton Marcel HAHN ${ }^{(1)}$ \\ Áquilas Nogueira MENDES(1) \\ (1) Faculdade de Saúde Pública, Universidade de São Paulo - USP, São Paulo, SP, Brasil.
}

Recebido: 28 jan 2019 Aceito: 10 fev 2019

Autor de correspondência: mmhahan@gmail.com

Conflito de interesses: Os autores declaram não haver nenhum interesse profissional ou pessoal que possa gerar conflito de interesses em relação a este manuscrito.

\section{Resumo}

A formação das regiões metropolitanas está intimamente ligada ao intenso crescimento urbano que se dá a partir do surgimento de diversos núcleos urbanos. Em torno destes, outros núcleos vão se agregando, formando um único aglomerado com relações e interações mútuas, fenômeno chamado de conurbação. Neste contexto, com o advento da Lei 8.080/90, importantes estratégias político-normativas foram criadas, com maior ou menor grau de pactuação, para impulsionar e/ ou efetivar a regionalização (Norma Operacional Básica - NOB, Núcleo de Objetos de Aprendizagem Significativa - NOAS, Pacto pela Saúde). Com isso, deu-se origem a três instrumentos para a gestão de um sistema regional de saúde: o Plano Diretor Regional - PDR; a Programação Pactuada Integrada - PPI; e o Plano Diretor de Investimentos - PDI. Em razão de a política de saúde ter sido definida constitucionalmente pelos princípios da universalidade e da igualdade no acesso à ações e serviços, os quais deveriam integrar uma rede regionalizada e hierarquizada, constituindo um sistema único, a partir da formação de redes assistenciais, estas normatizações não foram suficientes para superar os obstáculos à regionalização e à descentralização. Dessa forma, um novo desafio deve ser enfrentado pelos gestores do Sistema Único de Saúde - SUS, com vistas a efetivar o princípio da integralidade, observando a divisão de responsabilidades entre os atores envolvidos. Assim, o objetivo é constituir modelos para estruturação e descentralização dos sistemas de cogestão e organização dos serviços de saúde em redes, tendo em vista possibilitar o direcionamento equitativo da implementação das políticas públicas de saúde. Neste cenário, a regionalização é a diretriz do SUS que orienta a descentralização das ações e serviços de saúde, bem como os processos de negociação e pactuação entre os gestores. A articulação entre os gestores municipais para pactuação das referências intermunicipais dar-se-á por meio da PPI, que se trata de um instrumento que, em consonância com o processo de planejamento, visa definir e quantificar as ações de saúde para a população residente em cada território, além de nortear a alocação dos recursos financeiros a partir de critérios e parâmetros pactuados entre os gestores. Deve, ainda, explicitar os pactos de referência entre municípios e definir a parcela de recursos destinados à assistência da própria população e da população referenciada por outros municípios, possibilitando a reorganização dos processos de gestão e de 
regulação do sistema de saúde no âmbito dos estados, com vistas à melhoria do acesso do cidadão à rede de assistência a saúde. Com a promulgação do Decreto $n^{\circ} 7.508 / 2011$, surgiu a definição acerca dos espaços geográficos, indicados por agrupamentos de Municípios limítrofes, delimitado a partir de identidades culturais, econômicas e sociais e de redes de comunicação e infraestrutura de transportes compartilhados, com a finalidade de integrar a organização, o planejamento e a execução de ações e serviços de saúde, originando uma nova política por meio da qual os municípios e estados são incentivados a celebrarem o Contrato Organizativo de Ação Pública - COAP). Portanto, a regionalização da saúde se apresenta como um processo de mudança das práticas sanitárias no âmbito do SUS, o que implica considerar suas dimensões política, econômica, ideológica e técnica. Na política, busca-se a transformação do SUS por meio de um espaço regional, numa situação de poder compartilhado no qual se manifestarão diversos interesses de distintos atores sociais. $\mathrm{Na}$ dimensão econômica, procura-se na eficiência a racionalização dos recursos para se alcançar os resultados. Na ideológica, ao se estruturar na lógica das necessidades e demandas da população, implicitamente opta-se por um modelo de atenção à saúde cuja implantação tem nítido caráter de mudança cultural. E na dimensão técnica, exige-se a utilização e a produção de conhecimentos e tecnologias coerentes com o projeto político e ideológico, cumprindo dessa forma a proposta fundamental da garantia integral à saúde. Objetivo: o objetivo é revisar a literatura científica sobre a regionalização da saúde entre municípios vizinhos e seu impacto no tocante aos recursos financeiros envolvidos. Método: o trabalho se propõe à elaboração de uma revisão integrativa sobre o tema "regionalização da saúde entre municípios conurbados e o impacto nos recursos financeiros", no âmbito do SUS, levantando a produção científica disponível através da busca que envolve a sistematização e publicação dos resultados de uma pesquisa bibliográfica em saúde em plataforma de bases de dados da Saúde. A busca sistematizada foi realizada na plataforma BVS (http://bvsalud.org/ - Portal regional da BVS), partindo-se da técnica de funil, combinando-se diversos descritores relacionados ao tema e utilizando-se as sintaxes necessárias para refinar a busca. A composição sintática realizada do tema parte da compreensão de quatro polos temáticos de interesse, identificados a partir da pergunta da pesquisa: (a) estrutura de custos; (b) ciclo de vida; (c) estabelecimento assistencial de saúde (EAS); e (d) SUS. Considerações finais: atende a esse requisito principalmente a busca (i) $A N D$ (ii) $A N D$ (iii), resultando em 59 estudos identificados cuja sintaxe final é: (mh:("regionalização")) $O R$ (mh:("descentralização")) $O R$ (mh:("regionalização")) $O R$ (mh:("municipalização")) $O R$ (mh:("regionalização")) $O R$ (mh:("orçamento")) $O R$ (mh:("regionalização")) $O R$ (mh:("planejamento")), cujo objetivo final é analisar os avanços ocorridos desde a implantação do processo de regionalização, bem como identificar os obstáculos para a plena implementação.

Descritores: Regionalização; Orçamentos; Planejamento. 